\title{
AS RESPOSTAS IRLANDESAS À PESTE BUBÔNICA: ENTRE A MEDICINA E A RELIGIÃO
}

\section{Irish responses to the Bubonic Plague: between medicine and religion}

\author{
Raíssa Rocha Bombini \\ Doutoranda em História da Ciência \\ Programa de Estudos Pós-Graduados em História da Ciência da Pontifícia Universidade \\ Católica de São Paulo (PUC-SP) \\ ORCID: https://orcid.org/0000-0003-2562-287X \\ E-mail: rabombini@gmail.com
}

Recebido em: 13/10/2020

Aprovado em: 15/01/2021

\begin{abstract}
Resumo: A Peste Bubônica chegou à Irlanda provavelmente em 1348 e, assim como em outras partes da Europa, trouxe como consequência grande mortalidade e desespero entre a população. Apesar dessa temática ser bem conhecida nos meios acadêmicos, os impactos dessa calamidade foram sentidos em outros âmbitos pouco estudados até o momento, como na religião e na medicina irlandesas. Dessa forma, esse artigo é um estudo das manifestações religiosas e medicinais que surgiram na Irlanda após a chegada da pestilência sob o ponto de vista da História e da História da Ciência. Para esse propósito, utilizamos diversas fontes primárias, entre imagens, tratados médicos, cartas papais e Anais daquele período que trouxessem informações relevantes para compor uma análise mais ampla desses dois tipos de respostas à pandemia do século XIV ao XVI.
\end{abstract}

Palavras-chave: Irlanda; Idade Média; Peste Bubônica.

Abstract: The Bubonic Plague arrived in Ireland probably in 1348 and, as in other parts of Europe, it brought great mortality and despair among the population. Although this theme was well studied in academic circles, the impacts of this calamity reached other areas that have not been studied so far, such as Irish religion and medicine. Thus, this article is a study of the religious and medicinal manifestations that arose in Ireland after the arrival of the plague from the point of view of History and the History of Science. For this purpose, we used several primary sources, including images, medical treaties, papal letters and annals from that period that brought relevant information to compose a broader analysis of these two types of responses to the pandemic from the 14th to the 16th century.

Keywords: Ireland; Middle Ages; Bubonic Plague. 


\section{Considerações introdutórias}

A relação entre a Peste Bubônica e as respostas irlandesas à essa doença, ou seja, aquilo que foi feito para combatê-la em diversos âmbitos, como o religioso e o medicinal, é uma temática pouco explorada no meio acadêmico brasileiro e internacional. Os principais trabalhos feitos até hoje sobre a pestilência do século XIV na Irlanda abordaram, em geral, o que os Anais anglo-irlandeses e gaélico-irlandeses apresentaram sobre o período, isto é, informações sobre as mortes pelo território, os caminhos da doença, alguns eventos políticos e o sentimento de desolação. ${ }^{1}$

Por isso, buscamos analisar esse momento histórico sob uma nova perspectiva, que parte de diferentes fontes primárias para montar um quebra-cabeça que exponha manifestações de cunho religioso e medicinal à chegada da Peste Bubônica. Obviamente, não temos a pretensão de esgotar o tema proposto para o artigo, mas apenas iniciar a discussão, começando a montar as primeiras peças desse cenário, expondo algumas análises a partir das fontes que foram produzidas nesse período.

Vale ressaltar que o artigo também pode ser compreendido em um âmbito mais amplo, no qual a Irlanda está inserida em uma grande rede de transmissão de textos, pessoas e materiais, ligando-a a diversos centros de produção de conhecimento da Europa que geraram e espalharam ideias de tratamento e profilaxia sobre a Peste.

\section{A Peste Bubônica na Irlanda}

Em seu período, a Peste Bubônica foi chamada por vários nomes. Em versões latinas, era conhecida por "pestilência" (pestilentia), "mortalidade" (mortalitas), "grande mortalidade" (magna mortalitas) e "epidemia" (epidemia). ${ }^{2}$ Encontramos também, em manuscritos britânicos, a expressão "pestilens yvell", em Old English, que poderia ser traduzida por "pestilência maligna". Esses nomes reforçam o que a literatura e a arqueologia já expuseram, isto é, o poder devastador que essa doença teve quando chegou à Europa. Nos relatos irlandeses, por sua vez, a Peste foi chamada de "grande praga" ("plaidh mor") ${ }^{4}$, um nome igualmente adequado ao tamanho do infortúnio que ela causou à ilha (Gwynn, 1935: 25). 
A Peste Bubônica teria chegado à Irlanda vinda, primeiramente, do continente e, posteriormente, da Inglaterra, provavelmente por motivo das trocas econômicas com os condados do leste, como Louth. ${ }^{5}$ A tradição literária anglo-irlandesa traz o ano de 1348 como seu início no território. ${ }^{6}$ Essa narrativa está contida, por exemplo, nos famosos Anais de Frei Clyn, franciscano de Kilkenny, que também aponta algumas cidades do leste da Irlanda - Howth, Dalkey, Dublin e Drogheda - como as primeiras a receberem a doença. Outras fontes, geralmente de literatura gaélico-irlandesa, apontam o ano de 1349 e o oeste da Irlanda como o princípio da grande pestilência, como os Anais de Ulster, os Anais de Loch Ce e os Anais dos Quatro Mestres, que tiveram, aparentemente, uma fonte em comum (Annals of Ulster: 491; The Annals of Loch Ce: 3 e The Annals of Ireland: 139; Gwynn, 1935: 25).

Apesar de as fontes demonstrarem que a doença teria atingido a ilha de leste a oeste, os assentamentos anglo-irlandeses, compondo as maiores cidades nas costas leste, sudeste e sul, teriam sido os mais atingidos por ao menos uma década após a chegada da Peste. Mais especificamente, as vilas próximas ao mar e seus habitantes, geralmente pescadores e marinheiros, teriam sido os mais afetados. Enquanto isso, os assentamentos gaélico-irlandeses, dispersos por regiões montanhosas e menos populosas, teriam sofrido menos mortes, o que explicaria seu conhecimento mais tardio sobre a chegada da pestilência (Kelly, 2001: 14).

As crônicas anglo-irlandesas, mais completas do que as gaélico-irlandesas, trazem ainda outras informações importantes a respeito da Peste Bubônica. Relatam os óbitos, o avanço do contágio pelo território e os sintomas que os doentes apresentavam. Nesse sentido, sabemos pelos Anais de Frei Clyn, a principal testemunha textual da Peste em Dublin, Drogheda e em Kilkenny, de onde escrevia, que as duas primeiras cidades foram quase completamente destruídas poucas semanas após a chegada da pestilência. Somente em Dublin, quatorze mil pessoas teriam morrido dentro de poucos meses, além de vinte e três franciscanos. Reforça ainda o cenário catastrófico informando que quase não havia uma casa em que apenas um membro tivesse morrido, mas, via de regra, marido e mulher com seus filhos e toda a família pereciam com a Peste (Frater Johannes Clyn, 1809: vi; Gwynn, 1935: 27).

O número de mortes, no entanto, não era o único fator de assombro. A forma como a doença se mostrava nos corpos também era horrífica. Em seu relato sobre os 
sintomas da Peste, Frei Clyn expõe que as pessoas apresentavam furúnculos, úlceras e feridas que cresciam nas pernas e sob as axilas, enquanto outros sofriam de dores de cabeça e quase entravam em frenesi. Havia ainda aqueles que cuspiam sangue. Apenas após o sofrimento, a morte viria. $\mathrm{O}$ religioso menciona também que a pestilência era muito contagiosa, de forma que qualquer contato já seria o suficiente para que fosse transmitida (Frater Johannes Clyn, 1809: vi; Gwynn, 1935: 27).

Com a chegada desse cenário catastrófico à Irlanda e a transmissão de novos conhecimentos médicos pela Europa, algumas respostas ou manifestações logo começaram a aparecer. Entre elas, estão a busca por proteção divina, além da busca por preservação e cura pela medicina.

\section{A resposta religiosa}

A busca por proteção divina durante os surtos da Peste Bubônica na Irlanda permaneceu documentada em fontes textuais e imagéticas daquele período. A primeira a ser comentada aqui foi relatada pelo próprio Frei Clyn. O religioso escreveu que, em 1348, uma peregrinação teria ocorrido até a região de Thath Molyngis (ou Tech Moling, que significaria “Casa de Moling”), depois chamada de São Mullins (ou São Moling) ${ }^{7}$, localizada no condado de Carlow. Nessa região, haveria um monastério fundado por esse santo e bispo do século VII. O local teria guardado suas relíquias e já seria considerado um santuário e o destino de muitas peregrinações há muitos séculos (O'Hanlon, 1873: 723):

Também neste ano [1348], e principalmente em setembro e outubro, vieram juntos, de várias partes da Irlanda, bispos e prelados, clérigos e religiosos, senhores e outros, e comumente todas as pessoas de ambos os sexos, para a peregrinação e vadear as águas em Thath Molyngis, em tropas e multidões, de modo que você podia ver muitos milhares ali ao mesmo tempo por muitos dias juntos. Alguns vieram pelos sentimentos de devoção, mas outros, e eles eram a maioria, pelo medo da peste, que então cresceu muito [...]. ${ }^{8}$

Uma vez que a igreja de São Moling teria sido incendiada em 1323, junto com as relíquias do santo, é possível que a peregrinação tivesse as águas do local como uma nova forma de relíquia para os fiéis. As devoções eram focadas, portanto, em dois locais: o poço de São Moling e um curso de água que se dizia ter sido cavado pelo 
Santo. Isso explicaria a menção de Frei Clyn ao vadear as águas após a peregrinação (O'Hanlon, 1873: 720). Contudo, as histórias dos milagres do Santo também ajudariam a explicar a busca por esse recinto. Isso porque, de acordo com sua Vitae, São Moling teria curado um homem em cujo ouvido entrara um escorpião. O Santo teria ordenado que o animal peçonhento saísse do local, e assim ocorreu. Em seguida, São Moling teria curado o sangramento do ouvido desse homem (O'Hanlon, 1873: 716 e 717).

Ao menos duas associações entre essa história de São Moling e a busca por sua proteção no período da Peste Bubônica poderiam ser feitas a partir daqui. A primeira seria entre o veneno de um animal peçonhento e o veneno do ar pestilencial, uma associação bastante difundida na Idade Média. Nesse sentido, sabemos que pedras preciosas e gemas com o poder de proteger quem as portava de venenos ou de animais peçonhentos eram muitas vezes mencionadas em receitas médicas contra a Peste. É o caso, por exemplo, da esmeralda, conhecida como smaragdus. Em um dos principais tratados médicos sobre a Peste Bubônica, feito quando a doença surgiu na Europa, o Compendium de epidemia per collegium Facultatis Medicorum Parisius, a esmeralda foi descrita como "um medicamento notório contra todos os venenos"9 (Michon, 1860: 62). Dentro desse tratado, a esmeralda é mencionada, por exemplo, em uma receita médica com a descrição "Electuário do coração que preserva do ar venenoso, também da febre, e dos abscessos pestilenciais" (Michon, 1860: 69 e 70). Assim como a pedra preciosa era indicada para combater os venenos, de animais ou da Peste, São Moling e suas águas também teriam esse poder divino.

Ainda dentro dessa passagem, outra associação, mais abrangente, entre a história de São Moling e a Peste Bubônica estaria na cura do homem doente por algo maligno (o escorpião) e a cura dos afetados pela pestilência, também considerada um grande infortúnio. De um modo geral, poder-se-ia dizer que os fiéis buscariam a proteção contra o veneno pestilencial e a cura da doença ao peregrinarem, assim, à Thath Molyngis e entrarem em contato com as águas do local.

Essa não teria sido, no entanto, a única manifestação de uma resposta religiosa em grande proporção à chegada da Peste na Irlanda. Há ainda um segundo exemplo que poderia ser citado, registrado em uma carta enviada pelo Papa Clemente VI ao arcebispo de Armagh, na atual Irlanda do Norte, em 13 de novembro de 1349. A carta é um mandato ao arcebispo para alertar e induzir aquelas pessoas que se autodenominavam 
'flagellantes' a abandonarem essa "vã religião" (CPL 1342-62: 311). Uma carta de igual conteúdo parece ter sido enviada também ao arcebispo de Dublin na mesma data. Os flagellantes foram um movimento de caráter religioso que surgiu no norte da Itália no século XIII e se espalhou pela Europa. O grupo vagava pelas cidades em procissão, chicoteando-se em público para redimir seus pecados, incitando as populações a fazerem o mesmo. Em meados do século XIV, em virtude da grande pestilência ser vista como uma punição divina, o movimento ganhou força, chegando à Inglaterra e à Irlanda ainda em 1349. A Igreja os considerava heréticos e o Papa Clemente VI foi um dos grandes responsáveis por persegui-los e enfraquecer o movimento. ${ }^{10} \mathrm{~A}$ única informação sobre os flagellantes na Irlanda em 1349 está nessa carta, mas o fato de o movimento ter chamado a atenção do Papa e envolvido duas grandes arquidioceses irlandesas parece demonstrar que não foi um grupo insignificante. Ao mesmo tempo, a grande mortalidade no leste da ilha parece justificar sua presença justamente ali.

Nem todas as manifestações à chegada da pestilência, no entanto, envolveram multidões. Algumas repostas singulares também existiram. O primeiro exemplo a ser mencionado aqui encontra-se em um mural na parede norte do coro da Abadia Cisterciense em Knockmoy, Condado de Galway. Atualmente, a pintura está praticamente apagada pelas intempéries, mas algumas ilustrações completas desse mural sobreviveram em trabalhos dos séculos XVIII, XIX e início do XX. ${ }^{11}$

O mural em si, do século $\mathrm{XV}$, mostraria duas cenas: a cena superior traria a famosa história "Os três reis mortos e os três reis vivos" (Les Trois Rois Morts et les Trois Rois Vifs), uma lenda popular moralizante destinada a ilustrar a vaidade da grandeza humana. A imagem ainda seria acompanhada pela frase "Fomos como você é, você será como nós somos"12, reforçando a lenda (Crawford, 1919: 28). A cena inferior traria um homem imberbe amarrado a uma árvore, com flechas perfurando seu corpo. Em seus lados, haveria arqueiros apontando mais flechas. Essa cena ainda é acompanhada de um homem barbado sentado com um cilíndrico indistinguível em sua mão esquerda, enquanto mantinha a direita levantada (Crawford, 1919: 25-34).

O homem flechado apresentaria ao menos três significados relatados em diferentes bibliografias. Alguns autores consideraram ser a cena do martírio de São Cristóvão, cujas imagens eram bastante difundidas nas igrejas anglo-irlandesas. ${ }^{13}$ Contudo, na passagem do martírio de São Cristóvão, as flechas dos soldados não 
chegavam a atingi-lo, ficando flutuando ao seu redor (Jacopo de Vazzare, 2003: 575). Ao mesmo tempo, a figura mostra um jovem imberbe e pequeno, muito diferente da iconografia de um grande homem adulto geralmente atribuída ao Santo (Crawford, 1919: 26). Em outra interpretação, publicada no primeiro volume do The Dublin Penny Journal, em 1832, é dito que a cena retrataria um antigo costume irlandês, mostrando a morte de um jovem, o filho de Dermod Mac Murrough, rei de Leinster durante o século XII. Ao lado, o homem sentado representaria um Brehon, com um suposto rolo de leis em sua mão, tendo proferido sua sentença (Folds, 1832: 228 e 229). Parece pouco provável e esclarecedor, no entanto, que uma cena de caráter jurídico, com personagens pertencentes a outro reino e a outro período, tenha sido pintada em uma igreja do condado de Galway no início do século XV.

Pelos motivos elencados até aqui, devemos considerar uma terceira interpretação. Essa cena representaria o 'Martírio de São Sebastião', um dos santos patronos defensores contra a Peste Bubônica na Europa (Skemer, 2006: 178 e 255; Byrne, 2004: 95 e 96). São Sebastião foi um soldado romano martirizado pela sua crença cristã no século IV com flechadas (Jacopo de Vazzare, 2003: 181). Ao final do século XIV, o Santo passou a ser representado como um jovem seminu amarrado a um pilar e perfurado por várias flechas, o que explicaria a imagem na Abadia de Knockmoy. Alguns estudiosos, como o historiador Joseph Patrick Byrne, demonstram por meio da análise de imagens e textos medievais e renascentista que São Sebastião estava associado à pestilência por ter sobrevivido às flechadas e às feridas de seu martírio. A análise se basearia no fato de o Antigo Testamento mencionar repetidamente a flecha como uma metáfora para a punição divina. Dessa forma, a Peste Bubônica, também vista como um castigo de Deus, seria associada às flechas, enquanto São Sebastião receberia o status de um Santo poderosos contra a doença (Byrne, 2004: 94).

Ainda no mural supracitado, logo abaixo da imagem do Santo, havia a seguinte frase: "Ore pelas almas de Malachie O'Nollain e Conchubhui O'Eddichan, que me fizeram"14 (Crawford, 1919: 27). Apesar de essa fórmula ser comumente encontrada em monumentos medievais, o pedido por orações a São Sebastião pode remeter à grande mortalidade que a Peste Bubônica teria causado e ainda causava na Irlanda, principalmente se considerarmos que um novo surto se deu ainda ao final do século XIV e início do XV. Da mesma forma, a cena dos reis mortos poderia ser interpretada como 
uma maneira de lembrar os fiéis, especialmente os mais nobres, de que a morte viria para todos, algo que faria sentido em um momento de grande pestilência e desolação. Nessa interpretação, assim como na de São Cristóvão, a figura barbada seria a trindade: Deus, na figura de um homem velho, Cristo, na presença de uma suposta cruz, cujo braço seria a parte cilíndrica ainda visível, e o Espírito Santo, em uma suposta ave que já não está mais no mural (Crawford, 1919: 26).

Além dos Santos, que ganharam importantes papeis de protetores contra a pestilência nesse período, as orações e a busca pelas figuras de Cristo e de Maria também se destacaram como uma forma de se pedir proteção e cura. Maria, principalmente, tinha um triplo papel contra a Peste: era vista como a intercessora pelos pecadores diante de Cristo, o juiz; também como a própria protetora dos fiéis desesperados; e, ao mesmo tempo, era a imagem da pureza, associada ao corpo sem pecado e saudável, algo que deveria ser alcançado (Byrne, 2004: 94). Seu poder de cura foi reforçado nos poemas de Richard Ledrede (1275 - c.1360), bispo de Ossory ou Osraige, no sudeste da Irlanda. Em seus poemas, escritos entre 1317 e 1360, Ledrede escreveu sobre o poder de Maria para curar aquilo que estava inchado. Essa poderia ser uma referência aos abscessos pestilenciais, característica marcante da Peste Bubônica (Richard Ledrede, 1974: 71 - 73; Kelly, 2001: 46).

Outro exemplo da resposta religiosas à chegada da Peste à Irlanda seria uma pequena prece encontrada no manuscrito 1316 do Trinity College de Dublin, do século XIV. Nesse manuscrito, há um memorando em irlandês (fol. 36v), escrito por Hugh, filho de Conor Mac Egan (Mac Aodhágain), do ano 1350, que ele descreve ser o segundo ano da Peste. Esse memorando é acompanhado de um segundo, que contém uma oração pela preservação de si mesmo e de seus amigos durante esta praga, datado da noite de Natal $^{15}$ (TC MS 1316/2: fol. 36v). Os Mac Egan teriam sido, segundo registros, um clã com brehons ${ }^{16}$, poetas e clérigos, entre outros profissionais igualmente letrados. O manuscrito supracitado é um dos documentos mais antigos que os menciona, composto essencialmente de textos legais (Blake, 1909: 1 a 9).

Há, contudo, um texto médico muito importante que também compõe esse manuscrito. É um tratado em irlandês sobre a purificação do sangue ou, em um sentido mais amplo, do corpo, compreendendo passagens selecionadas e traduzidas do Expositio supra Antidotarium Nicolai, de Jean de Saint-Amand (1262-1312), médico 
parisiense (fol. 1r). Uma vez que a purificação do sangue, assim como a flebotomia, eram procedimentos importantes para a prevenção e a cura da Peste Bubônica ${ }^{17}$, esse texto médico poderia estar relacionado com a preocupação demonstrada na oração, isto é, a pestilência.

Nesse cenário, pode-se considerar que uma oração como a escrita por Hugh Mac Egan seria, além de uma busca por proteção, uma forma de amuleto textual. Amuletos textuais eram uma prática que consistia em escrever símbolos ou palavras com alguma eficácia mágica para buscar proteção, cura ou exorcismo de algum mal. Geralmente eram escritos em pedaços de pergaminhos e utilizados pendurados ou atados junto ao corpo. Contudo, há recorrências de tais amuletos nas marginalia de manuscritos. ${ }^{18}$

Don Skemer, que se dedicou ao estudo dos amuletos textuais, menciona alguns exemplos sendo utilizados contra a Peste Bubônica no século XIV e XV, entre os quais estão orações para São Sebastião. Um primeiro amuleto está presente no manuscrito francês BnF fr. 24957, do século XV. O suplicante pede a São Sebastião que o proteja da epidemia e menciona carregar a prece ou mantê-la na casa, o que ajuda a explicar a presença de orações em manuscritos que ficariam na residência, como o de Hugh Mac Egan (BnF MS fr. 24957; Skemer, 2006: 180 apud Rézeau, 1983: 460). Um segundo exemplo é encontrado no manuscrito italiano BL Additional MS 41600, também do século XV. A oração pede a São Sebastião que retire a pestilência (BL MS Additional 41600; Skemer, 2006: 180 e 181). Há ainda um terceiro exemplo de uma oração do século XV, no manuscrito italiano BR MS 1133, descrita como "Oração do gloriosíssimo São Sebastião, de máxima virtude contra a peste" ${ }^{\text {19 }}$ (BR MS 1133 [O.II.26]; Skemer, 2006: 181 apud Morpurgo, 1900: 165).

Os amuletos supracitados expõem preces com um intuito muito semelhante ao de Hugh Mac Egan em sua própria oração, ou seja, o pedido de proteção contra a pestilência. Isso nos faz considerar que a prece junto ao memorando irlandês seja, também, uma forma de amuleto textual, que protegeria a casa e seus habitantes, além de uma clara resposta religiosa ao infortúnio do século XIV. 


\section{A resposta medicinal}

Diferentemente da resposta religiosa à chegada da Peste Bubônica na Irlanda, representada pelas várias manifestações supracitadas, a resposta medicinal pareceu ser muito mais discreta à primeira vista. Encontramos apenas um tratado irlandês sobre a pestilência, localizado em três cópias, uma no manuscrito 24 P 26 do Royal Irish Academy, do século XV, e outras duas nos manuscritos E. 3. 30 e H. 3.7 do Trinity College de Dublin, do século XVI (Ó Corráin, 2017: 1044). Apesar de tardio e escrito em irlandês moderno, esse tratado anônimo é amplamente baseado em fontes mais antigas. Em um cenário mais amplo, o tratado ainda se insere em um movimento de novos textos médicos que surgiram na Europa como consequência da chegada da pestilência em 1348 e da falta de uma literatura médica que tratasse especificamente dessa doença, propondo meios de se evitá-la e tratá-la.

Geralmente, os tratados sobre a Peste eram divididos em três partes: a primeira abordaria as origens e causas da pestilência. A Peste era geralmente explicada em seu período pela teoria miasmática, segundo a qual o ar corrompido por vapores pútridos causaria doenças. Esse ar corrompido, também chamado muitas vezes de ar venenoso, entraria no organismo através dos poros da pele, especialmente quando dilatados por banhos ou por qualquer esforço físico. ${ }^{20}$ Uma segunda parte geralmente trataria do regime de prevenção, ou seja, condutas que deveriam ser tomadas a fim de se evitar o contágio. Uma grande preocupação dos médicos da época era de que os bulbos pestilenciais aparecessem perto dos órgãos essenciais, ou seja, o coração (abscessos na axila esquerda), o cérebro (abscessos atrás da orelha ou no pescoço) e o fígado (abscessos na virilha) ${ }^{21}$, conforme relatado parcialmente pelo Frei Clyn (Frater Johannes Clyn, 1809: iv). Por isso, recomendava-se que os órgãos fossem constantemente fortalecidos com remédios naturais feitos de ingredientes vegetais, minerais e animais, geralmente triturados ou dissolvidos em conservas. A terceira parte abordaria os tratamentos de cura da doença, também baseada em remédios como os citados acima, além de flebotomia. ${ }^{22}$

Os primeiros tratados médicos sobre a Peste foram produzidos, em geral, na França e na Itália ainda em 1348. A partir daí, passaram a ser estudados e copiados em outros centros e faculdades de medicina cada vez mais longínquos, espalhando-se pela 
Europa pelos séculos seguintes e dando origem, então, a mais tratados com novas ideias, ainda que a estrutura supracitada comumente se mantivesse. Esse é o caso do tratado encontrado nos manuscritos de Dublin, cuja estrutura lembra àquela dos primeiros tratados latinos (Ó Corráin, 2017: 1044).

A primeira parte do tratado irlandês consiste em explicar a causa da pestilência, baseando-se em Galeno e Ptolomeu. A causa primária seria o ar putrefato e corrompido que é formado pelos vapores vindos de cadáveres, terremotos ou de lugares com água parada, como esgotos. Aqui, o tratado menciona serem lugares onde vivem animais venenosos:

Pois esta é a causa disso [peste]: o ar putrefato malcheiroso que sobe de vapores terrestres grosseiros se misturando com as partes finas do ar, ou névoa grosseira que sobe de água estagnada, como fossos da cidade, e lugares onde moram sapos(?) e cobras venenosas e outros animais peçonhentos. (RIA MS 24 P 26: f. 151; TC MS E 3.30: 200; Wulff, 1926: 148 e 149)

A relação entre os animais peçonhentos, ou seus venenos, e a pestilência já foi abordada anteriormente no artigo. A causa secundária seria de origem astrológica, isto é, a guerra entre planetas. Por fim, o autor acrescenta a vingança de Deus e as estações perversas também como causas da pestilência, baseando-as na teoria humoral galênica e em Ptolomeu. Até aqui, o tratado parece ser amplamente baseado em tratados mais antigos, como os franceses e italianos feitos no século XIV (RIA MS 24 P 26: f. 151; TC MS E 3.30: 200; Wulff, 1926: 148 e 149).

A segunda parte do tratado traz o regime de prevenção. É recomendado que a pessoa permaneça em ar puro, principalmente observando a movimentação dos animais, que sempre o procuram. A explicação é dada da seguinte forma:

[...] pois Galeno diz que o ar fino claro é bom para a manutenção da saúde e que o sangue e os espíritos são purificados por ele; portanto, o ar puro é bom nesta temporada. Da mesma forma, tudo que diminui e evacua a corrupção dos humores em geral deve ser recomendado, pois como o ar puro e transparente (?) faz essas coisas, é melhor. (RIA MS 24 P 26: f. 151; TC MS E 3.30: 200 e 201; Wulff, 1926: 149)

Também é recomendada a busca por aquilo que fortaleça o coração, seguindo ideias hipocráticas: "Hipócrates diz que tudo o que conforta o coração e expulsa suas doenças, como syncope, cardiaca passio e semelhantes, é bom; portanto, uma vez que o 
ar puro exerce esses poderes, é melhor nesta temporada" (RIA MS 24 P 26: f. 151; TC MS E 3.30, p. 200 e 201; Wulff, 1926: 149). Nesse sentido, a boa alimentação também seria essencial para regular os humores. Deveria ser composta de comidas frias, tal como verduras e legumes, uma vez que a pestilência era quente (composta de febres). Da mesma forma, fragrâncias que elevassem o espírito deveriam ser utilizadas, tal como a de violetas e maças aromáticas. Para essa parte do tratado, o autor utiliza como autoridades, além do corpus hipocrático e galênico, "Gilbert", provavelmente Gilbertus Anglicus (c. 1180 - c. 1250), renomado médico inglês; Johannes Mesue, ou Yuhanna Ibn Masaway (? - 857); Almansor, ou al-Manșūr (c. 938 -1002); e um Magister Ricardus, não identificado. Há indícios de que o tratado irlandês ainda teria como fonte, além dessas citadas explicitamente, o Breviarium Bartholomei, de John Mirfield, um escritor eclesiástico e médico inglês que viveu durante os surtos de Peste Bubônica do final do século XIV, atuando no Convento e no Hospital St Bartholomew, em Londres (RIA MS 24 P 26: f. 151; TC MS E 3.30, p. 200 e 201; Wulff, 1926: 143,144, 149 e 150).

Ainda dentro dessa segunda parte do tratado, há uma descrição de doze regras supostamente expostas por Avicena, ou Ibn Sina (c. 980 - 1037), sobre as estações perversas. Por exemplo, o autor menciona que, caso o inverno fosse úmido e ventoso, com ventos do sul, e a primavera fosse seca, com ventos do nordeste, haveria muitos abortos e doenças entre as grávidas naquele ano (RIA MS 24 P 26: f. 151; TC MS E 3.30, p. 201 e 202; Wulff, 1926: 150 a 152).

O tratado termina com um pequeno estudo astrológico com explicações sobre as três ascensões dos corpos celestes e das estrelas, que o autor chamou de Cosmicus, Acronicus e Heliacus. Essa parte do tratado não menciona doenças e também não parece se conectar com as partes anteriores, com exceção, talvez, do brevíssimo comentário sobre a origem astrológica da pestilência na primeira parte do estudo (RIA MS 24 P 26: f. 151; TC MS E 3.30, p. 201 e 202; Wulff, 1926: 152).

Apesar de tardio, esse tratado traria informações importantes para a sobrevivência dos habitantes da Irlanda, principalmente na sugestão de se buscar regiões sem a putrefação de esgotos e cadáveres. Isso significaria evitar as regiões baixas e mais povoadas, próximas ao mar, onde a doença se espalhava com mais facilidade. 
Apesar de não termos conhecimento de mais tratados médicos sobre a Peste Bubônica feitos na Irlanda, outros textos médicos produzidos durante os períodos de surtos da doença também poderiam ser considerados uma forma de resposta médica à pestilência. É o caso, por exemplo, do tratado sobre a purificação do sangue encontrado no manuscrito 1316 do Trinity College de Dublin, do século XIV, mencionado anteriormente (TC MS 1316/2). Também poderia ser o caso do manuscrito 1318, igualmente do Trinity College, do início do século XV. Esse longo manuscrito contém alguns textos médicos, como um tratado lidando com feridas e úlceras (f. 437), o que poderia ser útil para os bulbos pestilenciais. Há também outro tratado sobre os quatro elementos (f. 477) e um comentário sobre os aforismos de Hipócrates (f. 487) (TC MS 1318; Abbott; Gwynn 1921, p. 94-110, com suplemento em p. 342-8).

Outro manuscrito que poderia fazer parte de nossa análise é o 1334 do Trinity College de Dublin, do século XV, inteiramente composto por textos médicos. Entre estes, estão outro tratado sobre feridas (f. 44) e duas listas alfabética de plantas, minerais e partes de animais usados na medicina, suas propriedades e a maneira de prepará-los, em latim e irlandês (f. 21) (TC MS 1334). Uma lista semelhante a essa é encontrada no manuscrito 1343, igualmente do Trinity College de Dublin e do século XV. Esse manuscrito também é formado inteiramente de tratados médicos, incluindo um sobre flebotomia e evacuações (TC MS 1343). A flebotomia era parte essencial da prevenção e do tratamento para a Peste Bubônica, aparecendo constantemente em tratados italianos e franceses. ${ }^{23}$

As listas farmacológicas também devem ser destacadas, uma vez que o uso de vegetais, mas também de minerais e de partes de animais, compunha os remédios do regime de prevenção, geralmente indicados para o fortalecimento do corpo (i.e. dos órgãos) e do espírito, além dos remédios para o tratamento daqueles já infectados pela Peste. O próprio tratado irlandês sobre a pestilência traz algumas fragrâncias aromáticas, cujas propriedades seriam de elevar o espírito, dentro de seu regime de prevenção, como exposto anteriormente.

Dessa forma, ainda que esses textos médicos não tenham sido especificamente sobre a Peste Bubônica, sua produção ou reprodução nesse período de grande infortúnio também pode ser explicada como uma resposta à doença. 


\section{Considerações finais}

É possível observar, a partir das análises aqui apresentadas, que a Irlanda não assistiu passivamente à chegada e à disseminação da Peste Bubônica a partir de 1348 ou 1349. Muitas manifestações de caráter religioso - como a busca por proteção e piedade divina - ou de caráter medicinal - com a criação de textos médicos para o tratamento da doença - ocorreram nesse período e ficaram registradas em diversos documentos, como os Anais monásticos, as cartas e decretos papais, os tratados medicinais, entre outras fontes. Dessa forma, é sempre necessário ao historiador, e especificamente ao medievalista, reunir as peças desse quebra-cabeça, cuja grande imagem demonstrará a expressão de um povo em meio a uma catástrofe e que, até o momento, não haviam sido montadas.

\section{Siglas}

$\mathrm{BL}=$ British Library.

$\mathrm{BnF}=$ Bibliothèque nationale de France.

$\mathrm{BR}=$ Biblioteca Riccardiana, de Florença

$\mathrm{CPL}=$ Calendar of Entries in the Papal Registers Relating to Great Britain and Ireland.

MS = Manuscrito

RIA = Royal Irish Academy, Dublin

$\mathrm{TC}=$ Trinity College de Dublin

\section{Manuscritos}

Biblioteca Riccardiana de Florença, MS 1133 [O.II.26].

Bibliothèque Nationale de France, MS fr. 24957.

British Library, Additional MS 41600.

Royal Irish Academy, MS 24 P 26. 
Trinity College de Dublin, MS E. 3. 30.

Trinity College de Dublin, MS H. 3. 7.

Trinity College de Dublin, MS 1316.

Trinity College de Dublin, MS 1334.

Trinity College de Dublin, MS 1343.

\section{Obras medievais}

ANNALS OF ULSTER, otherwise Annals of Senat; A chronicle of irish affairs. Trad. B. MacCarthy. Dublin: Alex. Thom \& Co., 1893, vol. II.

CALENDAR OF ENTRIES in the Papal Registers Relating to Great Britain and Ireland 1342-62. Calendar of selections from Papal Regesta. BLISS, W. H \& JOHNSON, C. Londres: H. M. Stationery Off., 1897, vol. III.

FRATER JOHANNES CLYN, Annalium Hiberniae Chronicon, Ad annum MCCCXLIX. Dublin: Irish Arch. Soc., 1809.

JACOPO DE VARAZZE. Legenda Áurea: Vida dos Santos. São Paulo: Companhia das Letras, 2003.

RICHARD LEDREDE. The Latin Poems of Richard Ledrede, O.F.M., Bishop of Ossory, 1317-1360. COLLEDGE, E. (ed.). Toronto: Pontifical Institute of Mediaeval Studies, 1974.

THE ANNALS of Ireland, tr. from the orig. Irish of the Four masters. Trad. Owen Connellan. Dublin: Bryan Geraghty, 1845.

THE ANNALS of Loch Ce; a chronicle of Irish affairs from 1014 to 1590 . Trad. William Maunsell Hennessy. Londres: Longman \& Co., Trubner \& Co.; Oxford: Parker \& Co.; Cambridge: Macmillan \& Co.; Edimburgo: A. \& C. Black; Dublin: A. Thom., 1871, vol. II. 


\section{Referências bibliográficas}

ABBOTT, Thomas Kingsmill; GWYNN, Edward. Catalogue of the Irish manuscripts in the Library of Trinity College, Dublin. Dublin; Londres: Cornell University Library, 1921.

AUTISSIER, Anne. Le sang des flagellants. Médiévales 27, 1994, p. 51-58.

BLAKE, Martin J. Two Irish Brehon Scripts: With Notes on the MacEgan Family. Journal of the Galway Archaeological and Historical Society, 6 (1), 1909, p. 1-9.

BYRNE, Joseph Patrick. The Black Death. Westport; Londres: Greenwood Press, 2004.

COCHRANE, Robert. Abbey Knockmoy, County Galway: Notes on the Building and "Frescoes". The Journal of the Royal Society of Antiquaries of Ireland 34 (3), 1904, p. 244-253.

COOPER, Austin. Antiquities of Abbeys, Castles, \& Towers in Ireland. Londres: sem casa editorial, 1785, vol. I.

CRAWFORD, Henry S. The Mural Paintings and Inscriptions at Knockmoy Abbey. The Journal of the Royal Society of Antiquaries of Ireland, Sixth Series, 9 (1), 1919, p. 25-34.

CREIGHTON, Charles. A History of Epidemics in Britain - from A.D. 664 to the Extinction of Plague. Cambridge: Cambridge University Press, 1891.

FOLDS, J. S. "Historic Sketch of the past and present state of the Fine Arts in Ireland", The Dublin Penny Journal 1 (1), 1832, p. 227 - 230.

GWYNN, Aubrey. The Black Death in Ireland. An Irish Quarterly Review 24 (93), 1935, p. $25-42$.

IRELAND BOARD OF PUBLIC WORKS. Eighty-first annual report of the Commissioners of Public Works in Ireland, with appendices. Londres: H.M. Stationery Office, 1913.

KEATING, Geoffrey. The History of Ireland from the Earliest Period to the English Invasion. Nova Iorque: P. M. Haberty, 1857. 
KELLY, Maria. A History of the Black Death in Ireland. Stroud, Gloucestershire; Charleston: Tempus, 2001.

. The Great Dying: The Black Death in Dublin. Stroud,

Gloucestershire; Charleston: Tempus, 2003.

. 'Unheard-of Mortality': The Black Death in Ireland. History

Ireland 9 (4), 2001, p. 12-17.

MORPURGO, Salamone. I manoscritti della R. Biblioteca Riccardiana di Firenze: Manoscriti italiani. Roma: s.e., 1900.

Ó CORRÁIN, Donnchadh (ed.). Clavis Litterarum Hibernensium: Medieval Irish Books \& Texts (c. 400 - c. 1600). Turnhout: Brepols, 2017, v. III.

O'HANLON, Rev. John. The Lives of the Irish saints. Londres, Dublin, Nova Iorque: The Catholic Publishing Society, 1873, vol. 6.

RÉZEAU, Pierre. Les prières aux saints en français à la fin du Moyen Age. Prières à um saint particulier et aux anges. Genève: Librairie Droz, 1982, v. 1.

SKEMER, Don C. Binding Words. Textual Amulets in Middle Ages. Pensilvânia: The Pennsylvania State University Press, 2006.

SMITH, Brendan. Crisis and Survival in Late Medieval Ireland: The English of Louth and Their Neighbours, 1330-1450. Oxford: Oxford University Press, 2013.

SUDHOFF, Karl. Pestschriften Aus Den Ersten 150 Jahren Nach Der Epidemie Des „schwarzen Todes“ 1348. XVIII. Pestschriften Aus Frankreich, Spanien Und England. Archiv Für Geschichte Der Medizin 17 (1/3), 1925, p. 12 - 139.

WULFF, Winifred. Tract on the Plague. Ériu, 10, 1926/1928, p. 143-154.

\section{Notas}

\footnotetext{
${ }^{1}$ Sobre a bibliografia que abordou a Peste Negra na Irlanda, vide as referências CREIGHTON, Charles. A History of Epidemics in Britain - from A.D. 664 to the Extinction of Plague. Cambridge: Cambridge University Press, 1891, 236; GWYNN, Aubrey. The Black Death in Ireland. An Irish Quarterly Review 24 (93), 1935, p. 25 -42; KELLY, Maria. A History of the Black Death in Ireland. Stroud, Gloucestershire, Charleston: Tempus, 2001; KELLY, Maria. The Great Dying: The Black Death in Dublin. Stroud, Gloucestershire, Charleston: Tempus, 2003; KELLY, Maria. 'Unheard-of Mortality': The Black Death in Ireland. History Ireland 9 (4), 2001, p. 12-17. Sobre os Anais produzidos no período,
} 
vide FRATER JOHANNES CLYN. Annalium Hiberniae Chronicon, Ad annum MCCCXLIX. Dublin: Irish Arch. Soc., 1809; THE ANNALS of Ireland, tr. from the orig. Irish of the Four masters. Trad. Owen Connellan. Dublin: Bryan Geraghty, 1845; THE ANNALS of Loch Ce; a chronicle of Irish affairs from 1014 to 1590. Trad. William Maunsell Hennessy. Londres: Longman \& Co., Trubner \& Co.; Oxford: Parker \& Co.; Cambridge: Macmillan \& Co.; Edimburgo: A. \& C. Black; Dublin: A. Thom., 1871, vol. II; ANNALS OF ULSTER, otherwise Annals of Senat; A chronicle of irish affairs. Trad. B. MacCarthy. Dublin: Alex. Thom \& Co., 1893, vol. II.

${ }^{2}$ Esses nomes aparecem em diferentes textos medievais, como no Compendium de epidemia per collegium Facultatis Medicorum Parisius, de 1348. Vide, por exemplo, MICHON, Joseph. Documents inédits sur la peste de 1348. Paris: J. B. Baillère et Fils, 1860.

${ }^{3}$ Essa denominação aparece no manuscrito Rawlinson A 429, fólio 85v, da seguinte forma: "Here begyns a nobyll tretys mayde of gude fisycyane John of Burdews for medicyn agayne the pestilens yvell".

${ }^{4}$ Vemos essa expressão, por exemplo, nos Anais de Loch Ce. Vide THE ANNALS of Loch Ce; a chronicle of Irish affairs from 1014 to 1590. Trad. William Maunsell Hennessy. Londres: Longman \& Co., Trubner \& Co.; Oxford: Parker \& Co.; Cambridge: Macmillan \& Co.; Edimburgo: A. \& C. Black; Dublin: A. Thom., 1871, vol. II, p. 2.

${ }^{5}$ Sobre esse assunto, vide SMITH, Brendan. Crisis and Survival in Late Medieval Ireland: The English of Louth and Their Neighbours, 1330-1450. Oxford: Oxford University Press, 2013.

${ }^{6}$ Uma segunda mão que continuou o trabalho de Frei Clyn após sua provável morte teria escrito nas margens do manuscrito 3. 20., preservado na Biblioteca do Trinity College de Dublin, que a pestilência teria retornado à Irlanda em 1362, depois em 1373, em 1382 e em 1391. Vide FRATER JOHANNES CLYN, Annalium Hiberniae Chronicon, Ad annum MCCCXLIX. Dublin: Irish Arch. Soc., 1809. p. 38.

${ }^{7}$ Sobre a vida de São Moling, vide O'HANLON, Rev. John. The Lives of the Irish saints. Londres; Dublin; Nova Iorque: The Catholic Publishing Society, 1873, vol. 6, p. 691 a 724.

${ }^{8}$ Traduação realizada pela autora. "Item, hoc anno et maxime mense Septembri et Octobri convenerunt undique de diversis partibus Hibernie, episcopi et prelati, viri ecclesiastici et religiosi, magnates et alii, et comuniter onnies utriusque sexus ad peregrinacionem et vadacioncm aque de Thaht-Moljngis, turmatim et in multtludine, sic ut multa milia hominum simul illuc multis diebus convenire videres, quidam venerunt devocionis aftectu, alii (sed plures) pestilencie metu, que tunc nimis invaluit" in FRATER JOHANNES CLYN, Annalium Hiberniae Chronicon, Ad annum MCCCXLIX. Dublin: Irish Arch. Soc., 1809. p. xxiv e 35.

9 "Smaragdus est etiam insignis medicina contra omne venenum". MICHON, Joseph. Documents inédits sur la peste de 1348. Paris: J. B. Baillère et Fils, 1860, p. 62. Tradução realizada pela autora.

${ }^{10}$ Sobre esse assunto, vide AUTISSIER, Anne. Le sang des flagellants. Médiévales 27, 1994, p. 51-58.

${ }^{11}$ Vide, por exemplo, COOPER, Austin. Antiquities of Abbeys, Castles, \& Towers in Ireland. Londres: sem casa editorial, 1785, vol. I ou IRELAND BOARD OF PUBLIC WORKS. Eighty-first annual report of the Commissioners of Public Works in Ireland, with appendices. Londres: H.M. Stationery Office, 1913.

12 "fuimus ut estis vos erttis ut sumus nos". In In CRAWFORD, Henry S. The Mural Paintings and Inscriptions at Knockmoy Abbey. The Journal of the Royal Society of Antiquaries of Ireland, Sixth Series, 9 (1), 1919, p. 28.

${ }^{13}$ Vide, por exemplo, IRELAND BOARD OF PUBLIC WORKS. Eighty-first annual report of the Commissioners of Public Works in Ireland, with appendices. Londres: H.M. Stationery Office, 1913. p. $42-44$.

14 "Orate pro animabus malachie $i$ nollain et conchubhui hi eddichan qui me fieri fecerunt". In CRAWFORD, Henry S. The Mural Paintings and Inscriptions at Knockmoy Abbey. The Journal of the Royal Society of Antiquaries of Ireland, Sixth Series, 9 (1), 1919, p. 27.

${ }^{15}$ Essa informação aparece também em ABBOTT, Thomas Kingsmill \& GWYNN, Edward. Catalogue of the Irish manuscripts in the Library of Trinity College, Dublin. Dublin, Londres: Cornell University Library, 1921. p. 90 e 91.

${ }^{16} \mathrm{O}$ Brehon (Breitheamh, em irlandês) exercia um papel de juiz ou expositor da lei dentro da cultura celta antiga e medieval na Irlanda, mantendo-se mesmo após a chegada do Cristianismo. Sobre esse assunto, vide, por exemplo, KEATING, Geoffrey. The History of Ireland from the Earliest Period to the English Invasion. Nova Iorque: P. M. Haberty, 1857. p. lvi.

${ }^{17}$ Menções à purificação do sangue e à flebotomia aparecem em diversos tratados médicos do período. Vide, por exemplo, MICHON, Joseph. Documents inédits sur la peste de 1348. Paris: J. B. Baillère et Fils, 1860 , p. 58 e 80. 
${ }^{18}$ Sobre os amuletos textuais, vide SKEMER, Don C. Binding Words. Textual Amulets in Middle Ages. The Pennsylvania State University Press, 2006.

19 "Oratio gloriossimi Sancti Sebastiani, virtutis maxime contra pesto". In SKEMER, Don C. Binding Words. Textual Amulets in Middle Ages. The Pennsylvania State University Press, 2006, p. 181 apud MORPURGO, Salamone. I manoscritti della R. Biblioteca Riccardiana di Firenze: Manoscriti italiani. Roma: s.e., 1900, p. 165.

${ }^{20}$ Essa informação é encontrada, por exemplo em MICHON, Joseph. Documents inédits sur la peste de 1348. Paris: J. B. Baillère et Fils, 1860. p. 57 e 58.

${ }^{21}$ Vemos referências a esses órgãos, por exemplo, no tratado de Johannes Jacobus, médico Real e Papal, além de Chanceler, de Montpellier, de 1364. SUDHOFF, Karl. Pestschriften Aus Den Ersten 150 Jahren Nach Der Epidemie Des „schwarzen Todes“ 1348. XVIII. Pestschriften Aus Frankreich, Spanien Und England. Archiv Für Geschichte Der Medizin 17, no. 1/3 (1925), p. 28.

${ }^{22} \mathrm{O}$ Compendium de epidemia per collegium Facultatis Medicorum Parisius, de 1348, é um exemplo de tratado com essa divisão, tendo servido como fonte para muitos outros. Vide MICHON, Joseph. Documents inédits sur la peste de 1348. Paris: J. B. Baillère et Fils, 1860.

${ }^{23}$ Vide, por exemplo, MICHON, Joseph. Documents inédits sur la peste de 1348. Paris: J. B. Baillère et Fils, 1860, p. 58. 